\title{
Penerapan Sistem Informasi Iuran Warga Griya Pataruman Asri Berbasis Website
}

\author{
Sopian Alviana*1, Bobi Kurniawan $^{2}$ \\ 1Program Studi Teknik Informatika, Fakultas Teknik dan Ilmu Komputer, Universitas Komputer Indonesia \\ ${ }^{2}$ Program Studi Teknik Elektro, Fakultas Teknik dan Ilmu Komputer, Universitas Komputer Indonesia \\ *e-mail: sopian.alviana@email.unikom.ac.id ${ }^{1}{ }^{\text {bobi@email.unikom.ac.id }}{ }^{2}$
}

\begin{abstract}
Abstrak
Griya Pataruman Asri 3 merupakan salah satu Perumahan yang terletak di daerah Cipatik Bandung Barat. Saat ini jumlah warga yang terdapat di perumahan tersebut meliputi kurang lebih 40 kepala keluarga. Dalam menunjang proses kegiatan warga, pada perumahan tersebut terdapat proses pembayaran iuran dan kas warga. Proses tersebut masih menggunakan proses manual, yaitu warga membayar dengan mendatangi perwakilan warga, kemudian membayar dan mencatat iuran pada lembar kertas yang disediakan. Kelemahan pencatatan iuran ini yaitu terdapat pada kurang transparansi terhadap penggunaan dana dan kesalahan dalam pengelolaan laporan. Kegiatan pengabdian kepada masyarakat ini bertujuan untuk menerapkan teknologi informasi dalam mengelola iuran dan kas warga. Hasil akhir dari kegiatan PKM adalah pembangunan dan penerapan system informasi iuran dan kas warga berbasis website. Sistem informasi dapat digunakan untuk mengelola data iuran dan laporan transparansi penggunaan dana warga.
\end{abstract}

Kata kunci: Sistem Informasi, Iuran, Website

Abstract
Griya Pataruman Asri 3 is one of the housing located in Cipatik area of West Bandung. Currently the number of residents in the housing includes approximately 40 heads of families. In supporting the process of citizen activities, in the housing there is a process of payment of dues and cash of residents. The process is still using a manual process, namely citizens pay by visiting a citizen's representative, then paying and recording dues on the provided paper sheet. The weakness of recording these dues is the lack of transparency over the use of funds and errors in the management of reports. This community service activity aims to apply information technology in managing the dues and cash of citizens. The final result of PKM activities is the development and application of a website-based citizen dues and cash information system. Information systems can be used to manage dues data and transparency reports on the use of citizen funds.

Keywords: Information System, Dues, Website

\section{PENDAHULUAN}

Griya Pataruman Asri merupakan perumahan yang terletak di Jalan Raya Cipatik, Desa Pataruman, Kecamatan Cihampelas, Kabupaten Bandung Barat. Perumahan ini memiliki bagian bagian perumahan sebanyak 3 tahapan. Masing - masing tahapan berjumlah 10 blok dan masing - masing blok berjumlah sekitar 20 rumah. Dalam menunjang kegiatan atau aktifitas warga pada perumahan, setiap warga harus membayar iuran warga yang dipergunakan untuk keamanan, kebersihan, dan kas warga. Pada perumahan biasanya terdapat pembayaran iuran dan kas warga diantaranya iuran keamanan, kebersihan dan kas warga [1]. Proses pembayaran uang iuran dan kas di Griya Pataruman masih menggunakan proses manual yaitu dengan melakukan pembayaran secara langsung kepada petugas, kemudian dicatat dan ditulis pada kertas anggota yang telah dibuat. Sistem pembayaran merupakan komponen penting dalam perekonomian terutama dalam menjamin transaksi pembayaran yang dilakukan. Sistem pembayaran juga berperan penting dalam mendukung system keuangan dan pelaksanaan kebijakan [2]. Proses pencatatan dengan menggunakan system manual, masih memiliki beberapa kelemahan diantaranya pencatatan dilakukan lebih banyak, kesalahan pencatatan, tidak ada tranparansi penggunaan dana, kesulitan mengetahui atau menyebarkan informasi kondisi keuangan warga secara langsung.

Perkembangan tenologi informasi saat ini telah memudahkan kehidupan manusia dengan berbagai produk teknologi [3]. Teknologi dapat memberikan dampak positif, 
meningkatkan minat dan bermanfaat jangka Panjang [4]. Transparansi dan laporan keuangan diperlukan dalam setiap kegiatan, agar memudahkan dalam pelaporan. Sistem informasi merupakan salah satu solusi yang dapat digunakan. Sistem informasi pembayaran iuran keamanan, kebersihan dan kas warga dapat membantu proses pencatatan dan pelaporan pemabayaran [5]. Penggunaan system informasi juga memberikan manfaat pada setiap pelaku kegiatan yaitu untuk petugas memudahkan proses pencatatan dan pengelolaan, serta untuk pengurus dan pengguna menjadi lebih terorganisir dengan baik [6]. Pemanfaatan teknologi informasi berupa website dapat membantu dalam penyebaran informasi [7]. System informasi dapat memudahkan setiap warga mendapatkan informasi dan dapat melihat informasi mengenai tagihan iuran yang dibayarkan dan laporan bulanan [8].

Berdasarkan beberapa permasalahan diatas, diperlukan sebuah system pencatatan informasi iuran warga yang dapat memudahkan dalam proses pencatatan, transparansi dana, serta pembuatan laporan. Maka melalui program pengabdian ini memberikan pemahaman dan penggunaan teknologi kepada warga untuk dapat dimanfaatkan sebagai system informasi yang dapat memberikan manfaat untuk proses pencatatan iuran.

\section{METODE}

Pada pelaksanaan kegiatan pengabdian kepada masyarakat ini terdiri dari beberapa tahapan yang dilaksanakan yaitu Perencanaan, Persiapan, Pengerjaan, Implementasi dan Evaluasi.

1. Tahapan Perencanaan, merupakan tahapan untuk membuat perencanaan mengenai kegiatan pengabdian kepada masyarakat. Bentuk kegiatan pada tahapan ini adalah membentuk tim pengabdian serta Menyusun proposal usulan pengabdian kepada masyarakat. Indikator yang harus dicapai pada tahapan ini adalah terbentuknya tim pengabdian serta tercapainya proposal usulan pengabdian.

2. Tahapan Persiapan, merupakan tahapan untuk penentuan tempat, pembuatan jadwal, serta Menyusun untuk kebutuhan terkait data yang dibutuhkan melalui survey atau observasi kepada masyarakat secara langsung. Indikator yang harus dicapai pada tahapan ini adalah hasil akhir penentuan tempat dan jadwal yang akan dilaksanakan untuk pengabdian kepada masyarakat. Selain itu, sudah mendapatkan hasil dari observasi untuk kebutuhan yang akan dilaksanakan saat pengabdian kepada masyarakat.

3. Tahapan Pengerjaan, merupakan tahapan penyusunan kebutuhan system pengabdian kepada masyarakat. Dalam hal ini, merupakan pengerjaan kebutuhan untuk Sistem Informasi Iuran Warga yang meliputi terhadap kebutuhan perangkat, database, penyusunan desain, dan pengerjaan pembuatan system sesuai dengan kebutuhan yang telah diidentifikasi pada tahapan sebelumnya. Indikator yang harus dicapai pada tahapan ini adalah daftar kebutuhan perangkat, system serta desain untuk aplikasi yang akan diterapkan kepada masyarakat.

4. Tahapan Implementasi, merupakan tahapan penerapan system informasi pada tempat Mitra masyarakat yang menjadi objek pengabdian, serta memberikan edukasi terhadap mitra terkait system yang akan digunakan, dan memberikan pendampingan selama penggunaan aplikasi yang telah dibuat. Indikator yang harus dicapai pada tahapan ini adalah berhasil memasang system yang telah dibuat, kemudian memberikan pendampingan kepada Mitra dalam penggunaan system tersebut.

5. Tahapan Evaluasi, merupakan tahapan akhir dalam pengabdian kepada masyarakat yang berguna untuk menampung dan mengevaluasi penerapan system informasi yang telah diterapkan guna untuk dijadikan perbaikan terhadap system agar dapat memberikan manfaat yang benar - benar dibutuhkan oleh masayarakat. Indikator 
yang harus dicapai pada tahapan ini adalah melakukan perbaikan terhadap system yang menyesuaikan terhadap kebutuhan dan masukan dari masyarakat. Evaluasi merupakan tahapan akhir dalam pengabdian yang dapat memberikan masukan terhadap kegiatan [9].

\section{HASIL DAN PEMBAHASAN}

Pada tahapan hasil dan pembahasan ini, merupakan hasil dari program pengabdian kepada masyarakat. Kegiatan pengabdian ini berlangsung selama 4 bulan dari bulan April - Juli 2021. Selama periode kegiatan berlangsung, dilakukan beberapa tahapan dimulai pengumpulan data, pembuatan aplikasi, penerapan aplikasi, pelatihan, serta evaluasi terhadap aplikasi yang telah dibuat.

1. Pengumpulan Data

Proses pengumpulan data merupakan tahapan awal yang dilakukan sebagai persiapan dalam pembuatan system informasi. Data awal ini menjadi data acuan untuk perubahan dari proses manual menjadi proses menggunakan teknologi informasi. Data tersebut diisi oleh setiap warga melalui pengisian secara online melalui Google Form, seperti berikut :

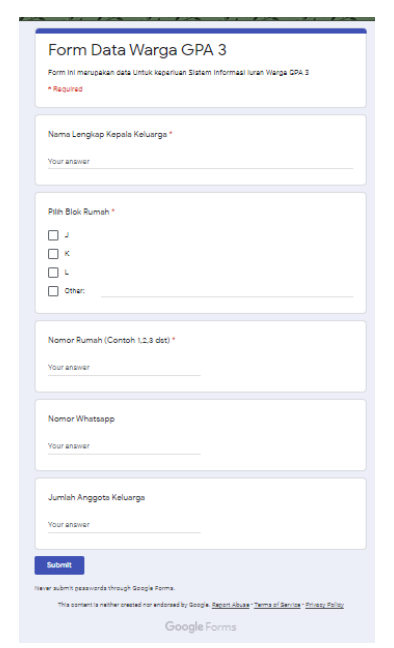

2. Perancangan Sistem

Gambar 1. Pengumpulan Data

Setelah proses pengumpulan data, kemudian dilakukan kebutuhan system yang akan digunakan oleh mitra. Maka, tahapan selanjutnya adalah pemodelan dan rancangan system. Model data dan rancangan system seperti tertuang pada use case gambar 1.

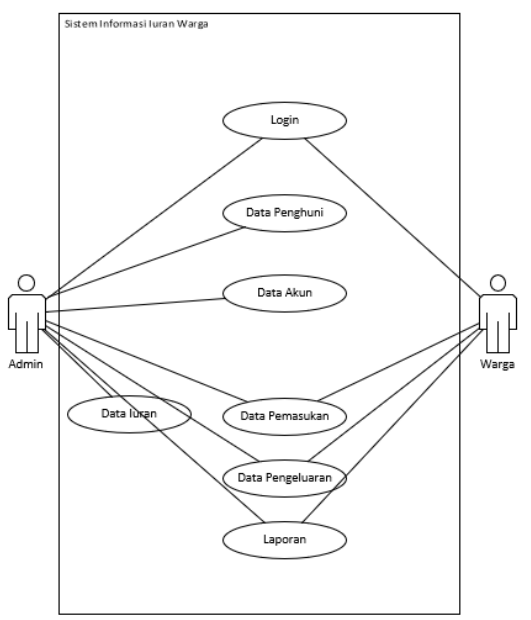

Gambar 2. Use Case Diagram 
3. Pembangunan Sistem

Pembangunan system dilakukan berdasarkan informasi data dan model rancangan yang telah dilakukan sebelumnya. Berikut hasil system informasi yang telah dibangun :

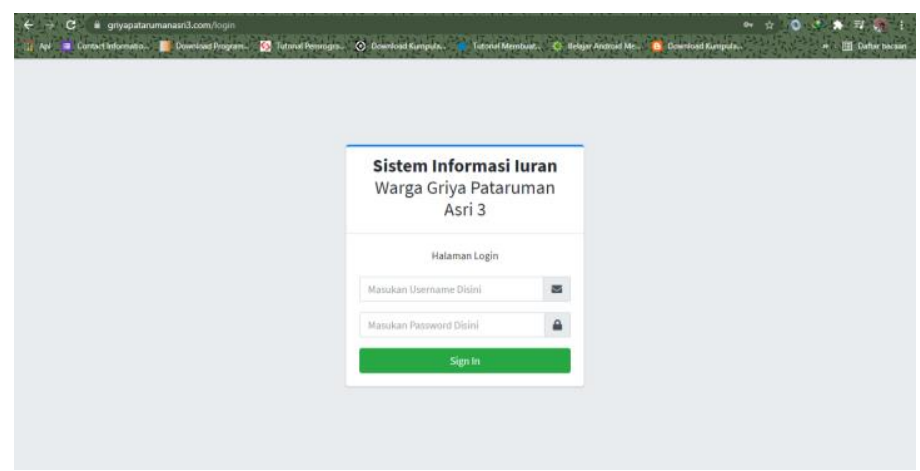

Gambar 3. Halaman Login



Gambar 4. Halaman Dashboard

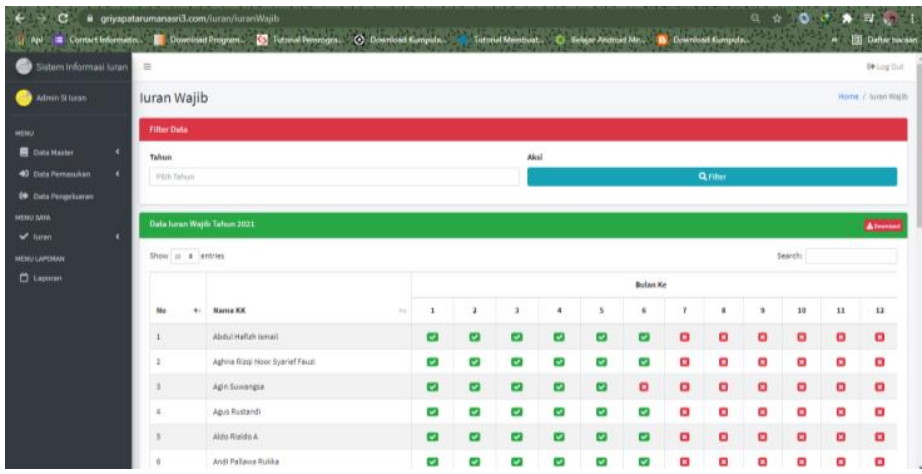

Gambar 5. Halaman Data Iuran Wajib

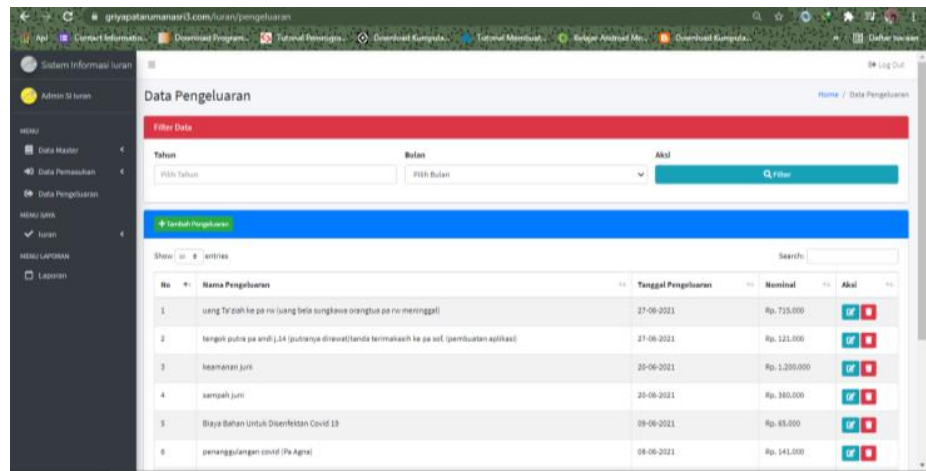

Gambar 6. Halaman Data Pengeluaran 


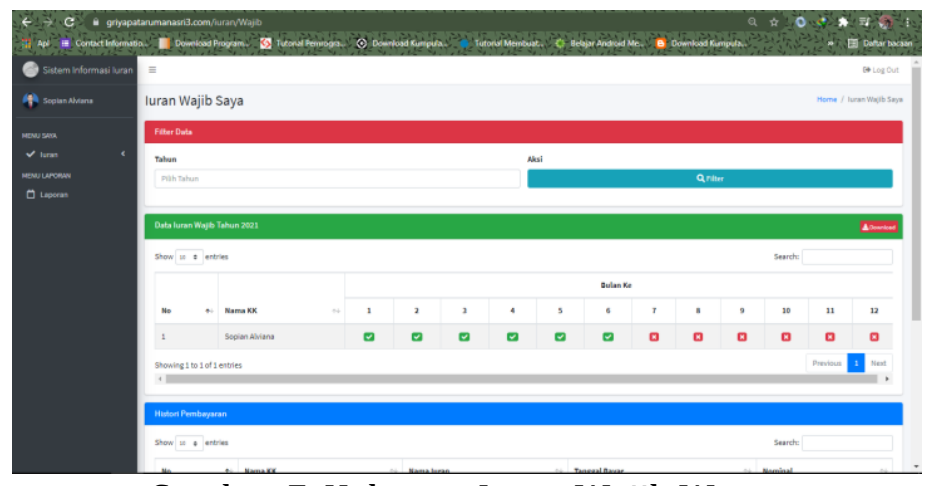

Gambar 7. Halaman Iuran Wajib Warga

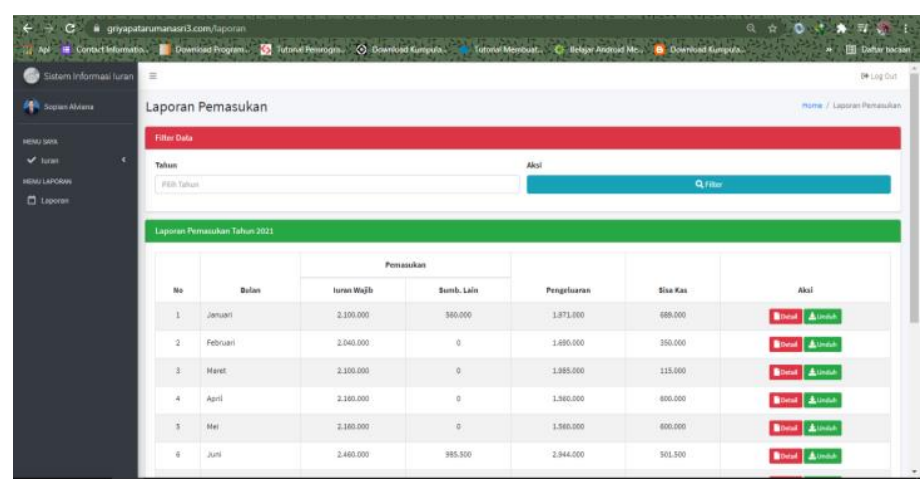

Gambar 8. Halaman Laporan



Gambar 9. Halaman Detail Laporan
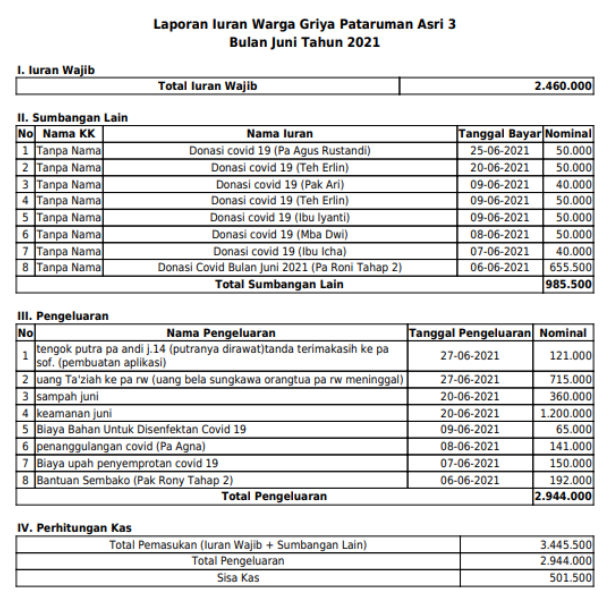

Gambar 10. File Laporan Iuran 
4. Pelatihan dan Penerapan Teknologi

Setelah system dibangun, maka dilakukan proses implementasi atau penerapan teknologi. Dikarenakan pada saat pelaksanaan pengabdian dengan masih tingginya kasus Covid 19. Maka, untuk memfasilitasi proses penerapan teknologi diberikan panduan berupa video penggunaan yang diunggah pada alamat https://www.youtube.com/watch?v=DrOCVbTuY w. Selain itu juga dilakukan sosialisasi dengan menggunakan fasilitas media sosail yaitu WA Group. Proses pendampingan dapat meningkatkan hasil dan tujuan pada pengabdian kepada masyarakat [10].

5. Evaluasi

Proses terakhir adalah proses evaluasi, merupakan proses evaluasi dari hasil penerapan system informasi iuran warga. Evaluasi meliputi evaluasi penerapan system, memeperbaiki masukan dan saran dari warga yang telah menggunakan aplikasi. Berikut salah satu masukan dan evaluasi yang diberikan oleh warga.

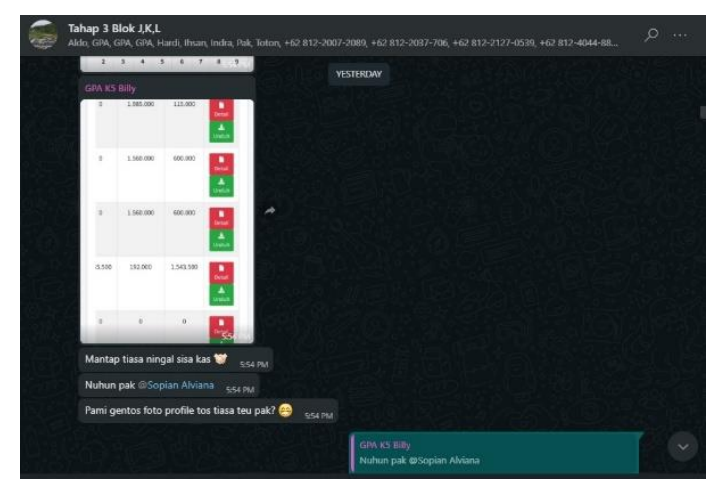

Gambar 11. Hasil Masukan Warga

Untuk mengetahui hasil evaluasi dan performa system informasi yang telah digunakan atau diimplementasikan, diberikan kuisioner terhadap 30 responden dari kalangan warga Griya Pataruman Asri. Hasil pengujian akhir berupa nilai persentase kepuasan terhadap pemakaian system.

Tabel 1. Soal Pernyataan Kuisioner

\begin{tabular}{cl}
\hline No & \multicolumn{1}{c}{ Isi Pernyataan Kuisioner } \\
\hline 1 & Kemudahan akses dan operasi system informasi \\
2 & Sistem informasi membantu dalam informasi iuran \\
3 & Kecepatan akses system informasi iuran \\
4 & Kelengkapan menu informasi iuran warga \\
\hline
\end{tabular}

Tabel 2. Jumlah Jawaban Kuisioner

\begin{tabular}{cccccc}
\hline Pernyataan & SK & K & C & B & SB \\
\hline 1 & 0 & 0 & 3 & 20 & 7 \\
2 & 0 & 0 & 1 & 15 & 14 \\
3 & 0 & 0 & 0 & 11 & 19 \\
4 & 0 & 0 & 0 & 10 & 20 \\
\hline
\end{tabular}

Tabel 3. Hasil Kuisioner

\begin{tabular}{ccc}
\hline Skor & Pernyataan & Hasil \\
\hline 1 & 0 & 0 \\
2 & 0 & 0 \\
3 & 4 & 12 \\
4 & 56 & 224 \\
5 & 60 & 300 \\
\hline
\end{tabular}


Secara perhitungan, persentase hasil kuisioner sebesar :

$$
\% \text { Maksimal }=\frac{536}{600} \times 100 \%=89,33 \%
$$

\section{KESIMPULAN}

Berdasarkan hasil pengumpulan data serta analisis kebutuhan yang telah dilakukan pada Warga Griya Pataruman Asri, didapatkan hasil bahwa Sistem Informasi Iuran Warga yang telah dibangun sangat membantu untuk proses pencatatan iuran warga. Hal ini dibuktikan dengan $89,3 \%$ warga puas dengan adanya system informasi ini. Selain sebagai pencatatan, sistem informasi juga memberikan manfaat dalam proses transparansi dan keterbukaan laporan keuangan iuran warga tersebut. Selain oleh petugas, semua warga juga sekarang dapat mengakses laporan keuangan warga secara langsung dan terbuka.

\section{UCAPAN TERIMA KASIH}

Penulis mengucapkan terima kasih kepada semua pihak yang telah berpartisipasi pada kegiatan pengabdian ini. Terutama kepada Warga Griya Pataruman Asri dan Divisi Pengabdian Kepada Masyarakat Universitas Komputer Indonesia.

\section{DAFTAR PUSTAKA}

[1] Putra, F. D. S., \& Iskandar, A. (2020). PERANCANGAN APLIKASI PEMBAYARAN IURAN KAS WARGA DI BANYU BIRU RESIDENCE BERBASIS ANDROID. eJournal Mahasiswa Akademi Telkom Jakarta (eMIT), 2(1), 36-42.

[2] Lintangsari, N. N., Hidayati, N., Purnamasari, Y., Carolina, H., \& Ramadhan, W. F. (2018). Analisis pengaruh instrumen pembayaran non-tunai terhadap stabilitas sistem keuangan di Indonesia. Jurnal Dinamika Ekonomi Pembangunan, 1(1), 47-62.

[3] Kustriyanti, S., Windana, F., \& Shofiya, A. (2018). Penerapan Sistem Informasi Pembayaran Iuran Berbasis Komputer pada Pusat Kegiatan Belajar Masyarakat Zamzam. JAST: Jurnal Aplikasi Sains dan Teknologi, 2(2), 35-42.

[4] Siregar, W., Irvan, I., \& Rahayu, E. (2020). SISTEM INFORMASI PEMBAYARAN IURAN KEAMANAN DAN KEBERSIHAN PADA PERUMAHAN BERBASIS WEBSITE MENGGUNAKAN METODE DESIGN THINKING. JITEKH Ournal Ilmiah Teknologi Harapan), 8(2), 50-58.

[5] Ramdhani, L. S., \& Mutiara, E. (2020). Penerapan Model Waterfall Pada Sistem Informasi Pengelolaan Iuran Rukun Kematian Yayasan Al-Hamidiyah Berbasis Web. Swabumi, 8(1), 21-28.

[6] Asana, I. M. D. P., Putra, P. S. U., \& Atmaja, K. J. (2020). Penerapan sistem informasi data iuran di sekretariat Warga Tutuan Gunaksa. Jurnal Anadara Pengabdian Kepada Masyarakat, 2(1).

[7] Ghozi, A. A., Hidayat, M. T., \& Rohman, K. (2020). SISTEM INFORMASI ANTAR WARGA "SIANWAR" SEBAGAI SOLUSI Bermasyarakat di PERUMAHAN TIGARAKSA BERBASIS WEB. JUST IT: Jurnal Sistem Informasi, Teknologi Informasi dan Komputer, 11(1), 45-52.

[8] Rahman, T., \& Nurdian, Y. (2021). Pendampingan Pemanfaatan Teknologi Digital Untuk Meningkatkan Pemasaran Toko Roti Di Pabian Sumenep. Dinamisia: Jurnal Pengabdian Kepada Masyarakat, 5(3).

[9] Imron, M., Krisbiantoro, D., \& Arsi, P. (2021). Peningkatan Kompetensi Bagi Siswa Melalui Pelatihan dan Pendampingan Jaringan Komputer Pada Sekolah Menengah Kejuruan Ma'arif NU 1 Karanglewas Purwokerto.Dinamisia: Jurnal Pengabdian Kepada 
Masyarakat, 5(3).

[10] Ismail, I., Gunaisah, E., Ulat, M. A., \& Poltak, H. (2021). Pelatihan Teknologi Sistem Informasi bagi Nelayan pada Masa Covid-19 di Era Digital. Dinamisia: Jurnal Pengabdian Kepada Masyarakat, 5(3). 